\title{
Use Of The High-Energy X-ray Microprobe At The Advanced Photon Source To Investigate The Interactions Between Metals And Bacteria
}

\author{
K. M. Kemner, ${ }^{1}$ B. Lai,${ }^{1}$ J. Maser, ${ }^{1}$ M. A. Schneegurt, ${ }^{2}$ Z. Cai, ${ }^{1}$ \\ P. P. Ilinski, ${ }^{1}$ C. F. Kulpa, ${ }^{2}$ D. G. Legnini, ${ }^{1}$ K. H. Nealson, ${ }^{3}$ S. T. Pratt, ${ }^{1}$ \\ W. Rodrigues, ${ }^{1}$ M. Lee Tischler, ${ }^{4}$ W. Yun ${ }^{5}$ \\ 1. Argonne National Laboratory, Argonne, IL 60439, USA \\ 2. University of Notre Dame, Notre Dame, IN 46556, USA \\ 3. Jet Propulsion Laboratory, Pasadena, CA 91109, USA \\ 4. Benedictine University, Lisle, IL 60532, USA \\ 5. Lawrence Berkeley National Laboratory, Berkeley, CA 94720, USA

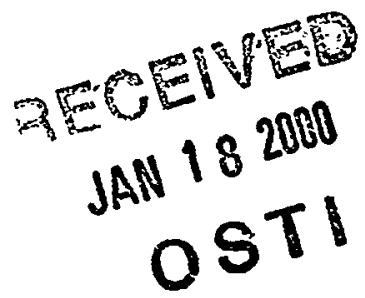

\begin{abstract}
Understanding the fate of heavy-metal contaminants in the environment is of fundamental importance in the development and evaluation of effective remediation and sequestration strategies. Among the factors influencing the transport of these contaminants are their chemical speciation and the chemical and physical attributes of the surrounding medium. Bacteria and the extracellular material associated with them are thought to play a key role in determining a contaminant's speciation and thus its mobility in the environment. In addition. the microenvironment at and adjacent to actively metabolizing cell surfaces can be significantly different from the bulk environment. Thus, the spatial distribution and chemical speciation of contaminants and elements that are key to biological processes must be characterized at micron and submicron resolution in order to understand the microscopic physical, geological, chemical, and biological interfaces that determine a contaminant's macroscopic fate. Hard X-ray microimaging is a powerful technique for the element-specific investigation of complex environmental samples at the needed micron and submicron resolution. An important advantage of this technique results from the large penetration depth of hard X-rays in water. This advantage minimizes the requirements for sample preparation and allows the detailed study of hydrated samples. This paper presents results of studies of the spatial distribution of naturally occuring metals and a heavy-metal contaminant $(\mathrm{Cr})$ in and near hydrated bacteria (Pseudomonas fluorescens) in the early stages of biofilm development, performed at the Advanced Photon Source Sector $2 \mathrm{X}$-ray microscopy beamline.
\end{abstract}

\section{ENVIRONMENTAL RESEARCH}

Chemical contamination of soil and groundwater is a universal problem of immense complexity and great global concern. Sources of contamination include past and present agricultural and industrial activities, operations at national defense sites, and mining and manufacturing processes. Assessment of thousands of hazardous waste sites in the United States alone (including over 1,200 on the National Priority List) has identified the presence of an array of toxic substances. These include heavy metals (such as $\mathrm{Pb}$, $\mathrm{Cr}, \mathrm{As}, \mathrm{Zn}, \mathrm{Cu}, \mathrm{Cd}, \mathrm{Ba}, \mathrm{Ni}$, and $\mathrm{Hg}$ ), radionuclides (including $\mathrm{U}, \mathrm{Pu}, \mathrm{Sr}, \mathrm{Cs}, \mathrm{Co}$, and $\mathrm{Tc})$, and potentially hazardous anions such as arsenate, chromate, and selenate.' The 


\section{DISCLAIMER}

This report was prepared as an account of work sponsored by an agency of the United States Government. Neither the United States Government nor any agency thereof, nor any of their employees, make any warranty, express or implied, or assumes any legal liability or responsibility for the accuracy, completeness, or usefulness of any information, apparatus, product, or process disclosed, or represents that its use would not infringe privately owned rights. Reference herein to any specific commercial product, process, or service by trade name, trademark, manufacturer, or otherwise does not necessarily constitute or imply its endorsement, recommendation, or favoring by the United States Government or any agency thereof. The views and opinions of authors expressed herein do not necessarily state or reflect those of the United States Government or any agency thereof. 


\section{DISCLAIMER}

Portions of this document may be illegible in electronic image products. Images are produced from the best available original document. 
output.

PACS number(s): 07.75, 91.65.D, 52.50.G, 29.17 


\section{INTRODUCTION}

The elements in the actinide region have traditionally been detected by alpha spectrometry and mass spectrometry but both methods have limited sensitivity for low-abundance isotopes. AMS has been recently expanded towards improved sensitivity detection of actinide elements using tandem accelerators [1-5]. Substantial progress has been made also in Thermal-Ionization Mass Spectrometry (TIMS) of minor isotopes through the additional use of a Retarding Potential Quadrupole Lens $[6,7]$.

On the other hand, the positive-ion Electron Cyclotron Resonance (ECR) Ion Source was developed, since first invented by R. Geller [8] thirty years ago, to produce high-intensity beams of multiply charged ions. The highly charged ions enhanced significantly the energy performance of heavy-ion accelerators. In this work, ECR is used as an ion source for accelerator mass spectrometry. It has the attractive feature that the efficient production of high-charge state ions ensures the elimination of molecular ions at the source stage, owing to their dissociation in collisions with fast electrons analogous to the stripping process used in conventional tandem AMS. The experiments were performed at the ATLAS accelerator $[9,10]$ at Argonne National Lab. using the high-power, 700-Watt, 10-GHz, ECR-1 source $[11,12]$. The linear acceleration based on velocity matching (phase requirements between resonators) together with the magnetic beam transport system act as a powerful mass and background filter. The ions were further separated and identified in the Fragment Mass Analyzer (FMA) system [13]. We demonstrate an extremely high isotopic abundance sensitivity of $1 \times 10^{-14}$ for $\mathrm{Pb}$ isotopes. A high sensitivity detection of ${ }^{236} \mathrm{U}\left({ }^{236} \mathrm{U} / \mathrm{U} \gtrsim 1 \times 10^{-12}\right)$ is feasible by AMS based on the ECR-ATLAS-FMA system. 


\section{EXPERIMENTAL SETUP}

Samples were prepared as pressed $\mathrm{U}_{3} \mathrm{O}_{8}+\mathrm{C}$ cathodes and the ECR source was operated in the sputtering mode [11]. A magnetic analysis of the ion beam out of the ECR source is shown in figure 1 and shows the charge distribution of $U$ ions. ${ }^{236} U^{21+}$ ions were extracted from the source and accel-decel, without further stripping, to $235 \mathrm{MeV}$. The accel-decel mode allows to further constrain the phase-matching conditions without unnecessary increase in beam energy. ${ }^{236} \mathrm{U}^{39+}(10 \%)$ ions were detected in a large-area Si detector in the focal plane of the FMA, after stripping in a $60 \mu \mathrm{g} / \mathrm{cm}^{2} \mathrm{C}$ target. Time-of-flight and $\mathrm{RF}$ time-of-flight of the ions were measured to enhance mass discrimination. In order to tune the accelerator system, a beam of ${ }^{124} \mathrm{Xe}^{11+}$ ions of nearly the same mass-to-charge ratio $(\Delta(m / q) /(m / q)$ $=2.1 \times 10^{-3}$ ) is used as pilot beam for ${ }^{236} \mathrm{U}^{21+}$. The large number of available (enriched) stable isotopes and charge states of Xe should allow the choice of an optimal pilot beam for various long-lived actinides to be detected with our system, apart from ${ }^{236} \mathrm{U}$. In a preliminary set of experiments, the isotopic abundance sensitivity of the system was studied by tuning accelerator and FMA to ${ }^{207} \mathrm{~Pb}$ ions and injecting (attenuated) beams of neighboring ions of ${ }^{206,208} \mathrm{~Pb}$. Figure 2 illustrates the suppression power of the different stages of the system. The overall abundance sensitivity is shown to be as high as $1 \times 10^{-14}$. The ECR efficiency for lead ions, at peak charge state, extracted from the sputter cathode is $0.4 \%$ [11].

\section{RESULTS AND CONCLUSIONS}

The history of beam production and cross talk between successive samples in the ECR source proved to be a major concern in our experiments. Background of $\mathrm{Pb}$ ions (mainly ${ }^{207} \mathrm{~Pb}$, originating in the extensive use of $\mathrm{Pb}$ in ATLAS experiments and of rather long memory), was particularly intense. We have however shown that (i) interferences of parasitic ${ }^{A} \mathrm{~Pb}^{q+}$ beams can be reduced by a large enough factor $\left(\gtrsim 10^{5}\right)$ through careful selection of 
the accelerated charge state of the desired ion $\left(21^{+}\right.$for $\left.{ }^{236} \mathrm{U}\right)$; (ii) the memory of the ${ }^{124} \mathrm{Xe}$ pilot beam in the ion source is very short ( 1 hour) and essentially zero after source flushing with $\mathrm{N}_{2}$. As seen in fig.3, a large number of groups of background ions $(\mathrm{m} / \mathrm{q}$ degeneracies) are still observed : they are however well resolved in FMA position and energy and do not pose count rate problems. Slits in front of the FMA focal plane can also be closed around a selected ${ }^{236} \mathrm{U}$ charge state to reduce count rate if necessary.

An unexpected result of the experiment was the observation of relatively high count rates of ${ }^{236} \mathrm{U}$ from a sample (mixed $\mathrm{U}_{3} \mathrm{O}_{8}+$ graphite) prepared from a uranium Standard Reference Material (NBS 950b, fig. 3). These count rates correspond to an isotopic abundance ${ }^{236} \mathrm{U} / \mathrm{U}$ of several ppm. Additional runs showed similar abundances from a metallic sample of depleted $U$ and a sample ${ }^{d e p} \mathrm{UO}_{2}+\mathrm{C}$, prepared from materials used in the past to produce ${ }^{238} \mathrm{U}$ beams in the ECR source. The concentration of ${ }^{236} \mathrm{U}$ in $950 \mathrm{~b}$ NBS Standard was later confirmed in an independent AMS experiment done at the Koffler Pelletron accelerator $[4,5]$. The history of the NBS 950 series Standard Reference Material and of the depleted U materials and the exact source of these ${ }^{236} U$ concentrations has not been cleared out. There is little doubt they must originate from nuclear reactor operation (see also [14]) and have probably been introduced into the Standard Material in the course of commercial processing. As a consequence of the very high ${ }^{236} \mathrm{U}$ content of NBS 950b Standard material, used in the ECR source to optimize yield of $U^{q+}$ ions, ${ }^{236} \mathrm{U}$ concentrations in natural minerals could not be reliably determined. Indeed, high count rates of ${ }^{236} \mathrm{U}$ were observed after retraction of the $950 \mathrm{~b}$ sample, with or without a new sample being introduced, due to the source memory effects. On the other hand, these findings prompted us to develop a method to reduce crosstalk between samples, using an $\mathrm{Al}$ liner to cover the ion source walls. A reduction factor of 100 to 150 in the ${ }^{236} \mathrm{U}$ background rate was observed. In these conditions, the isotopic ratio measured for a sample of U-rich ( $50 \% \mathrm{U}$ ) uraninite mineral from Joachimsthal (Bohemia) was of the order of $1 \times 10^{-10}$ (fig.4), in agreement with the isotopic ratio measured using tandem AMS [5].

Using the measured ECR-FMA transmission of $(10 \%)$, the $39^{+}$charge state fraction 
(10\%) and a ${ }^{238} \mathrm{U}^{21+}$ output of $0.5 \mu \mathrm{A}$ at the $\mathrm{ECR}$, we calculate a rate of 50 counts ${ }^{236} \mathrm{U}^{39+}$ per hour for a ${ }^{236} \mathrm{U}$ isotope ratio of $1 \times 10^{-11}$. The sensitivity is mainly limited by the ECR source output. We believe that, when the memory and cross-talk problems of the ECR ion source are properly handled, ultra-high sensitivity AMS measurements of rare actinides can be performed.

\section{ACKNOWLEDGEMENTS}

We gratefully acknowledge the careful operation of the ATLAS accelerator under this unusual mode of work. One of us (D.B.) gratefully acknowledges the support of IAEA through a Technical Cooperation grant (Project Nr. ISR/2/012). Work supported by the U.S. Department of Energy, Nuclear Physics Division, under contract W-31-109-ENG-38. 


\section{REFERENCES}

[1] X-L Zhao, M-J Nadeau, L. R. Kilius, and A. E. Litherland, Nucl. Instr. and Meth. B 92(1994)249.

[2] L. K. Fifield, R. G. Cresswell, M. L. diTada, T. R. Ophel, J. P. Day, A. P. Clacher, S. J. King and N. D. Priest, Nucl. Instr. Meth. B 117(1996)295. .

[3] L. K. Fifield, A. P. Clacher, K. Moris, S. J. King, R. G. Cresswell, J. P. Day and F. R. Livens, Nucl. Instr. Meth. B 123(1997)400.

[4] D. Berkovits, S. Ghelberg, A. Hershkowitz, E. Navon and M. Paul, Chinese Science Bulletin 43(1998)9.

[5] D. Berkovits, H. Feldstein, S. Ghelberg, A. Hershkowitz, E. Navon and M. Paul, Contribution to AMS-8, Vienna Sep.5-10, 1999, submitted to Nucl. Instr. and Meth. B , (2000).

[6] D.A. Papanastassiou, M.T. Benius, J.C. Chen and G.J. Wasserburg, ICOG-8, USGS Circular 1107(1994)242.

[7] S. Richter, A.Alonso, W. De Bolle, R.Wellum and P.D.P. Taylor, Int. J. of Mass Spect. and Ion Proc., 193(1999)9.

[8] R. Geller. Electron Cyclotron Resonance Ion Source and ECR Plasmas. IOP Publishing, NY, (1996).

[9] L. M. Bollinger, R. C. Pardo, K. W. Shepard, P. j. Billquist, J. M. Bogaty, B. E. Clifft, R. Harkewicz, F. H. Munson, J. A. Nolen and G. P. Zinkann, Nucl. Instr. and Meth. B 79(1993)753 .

[10] G. P. Zinkann, P. Billquist, J. Bogaty, B. Clifft, F. Munson, K. Nakagawa, J. Nolen, R. Pardo, K. W. Shepard, J. Specht, A. Sutherland, B. Tieman and I. Tilbrook, Nucl. Instr. and Meth. A 382(1996)132 . 
[11] R. Harkewicz, P. J. Billquist, J. P. Greene, J. A. Nolen Jr. and R. C. Pardo, Rev. Sci. Instrum. B 66(1995)2883 .

[12] R. Harkewicz, P. J. Billquist, and R. C. Pardo, Proceedings of the $12^{\text {th }}$ international workshop on ECR Ion Sources, Editors, M. Sekiguchi and T. Nakagawa, Riken, Japan, April 25-27, 19 , (1995).

[13] C. N. Davids, B. B. Back, K. Bindra, D. J. Handerson, W. Kutschera, T. Lauritsen, Y. Nagame, P. Sugathan, A. V. Ramayya and W. B. Walters Nucl. Instr. and Meth. B 70(1992)358.

[14] J. L. Iturbe, Appl. Radiat. Isot. 43(1992)817. 


\section{FIGURES}

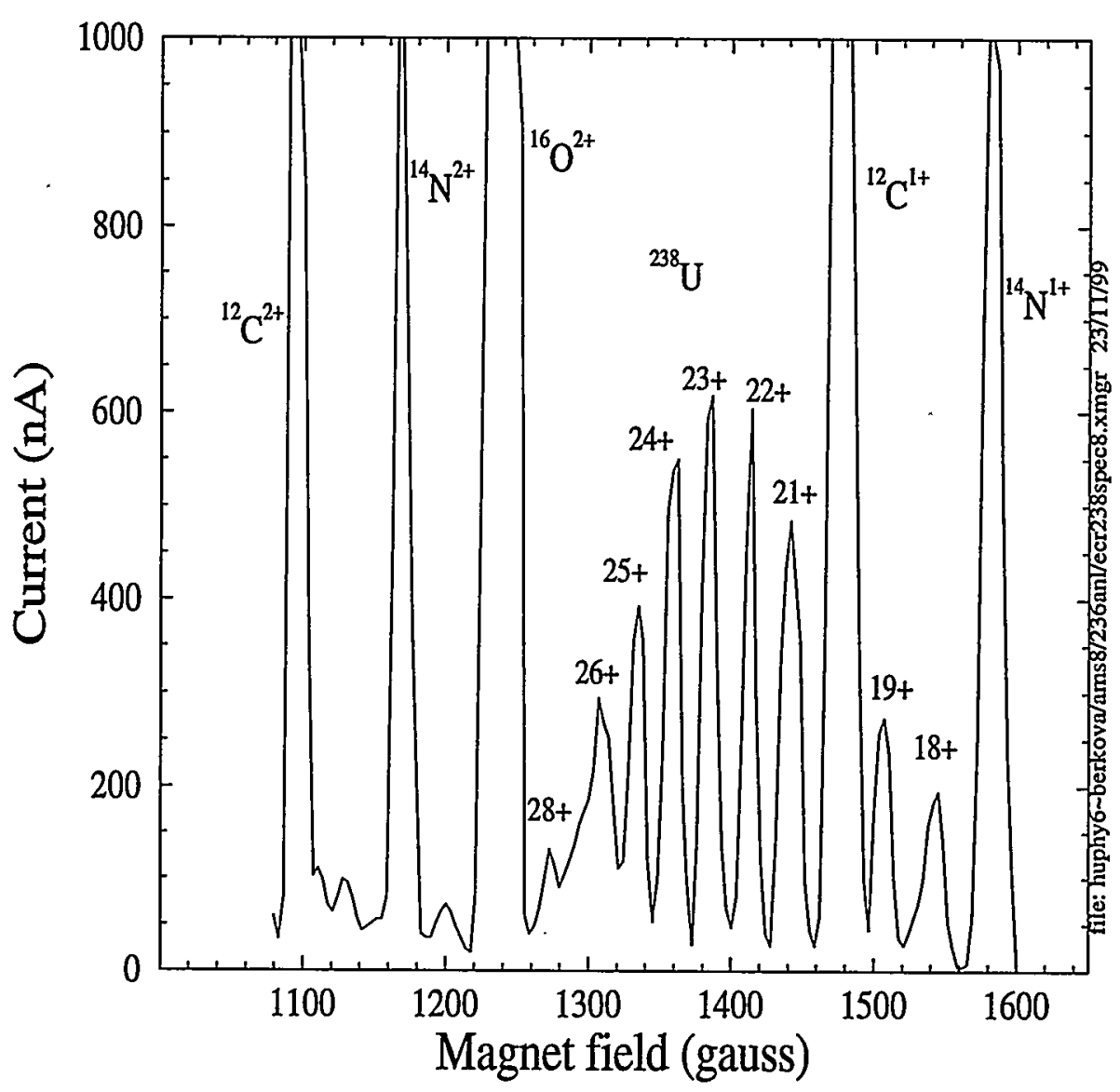

FIG. 1. ECRIS mass over charge $(\mathrm{m} / \mathrm{q})$ spectrum. The beam was analyzed by a $90^{\circ}$ low-resolution magnet and measured in the ECR HV platform Faraday cup. A natural pitchblende $\left(\mathrm{U}_{3} \mathrm{O}_{8}\right)$ sample mixed with graphite was used in the sputtering position and biased with $2.3 \mathrm{kV}$. Oxygen was used as a support gas for the ECR plasma. The electrons in the plasma were driven by a 630 Watt microwave power. The ions were extracted from the source with a potential of $14.0 \mathrm{kV}$. 


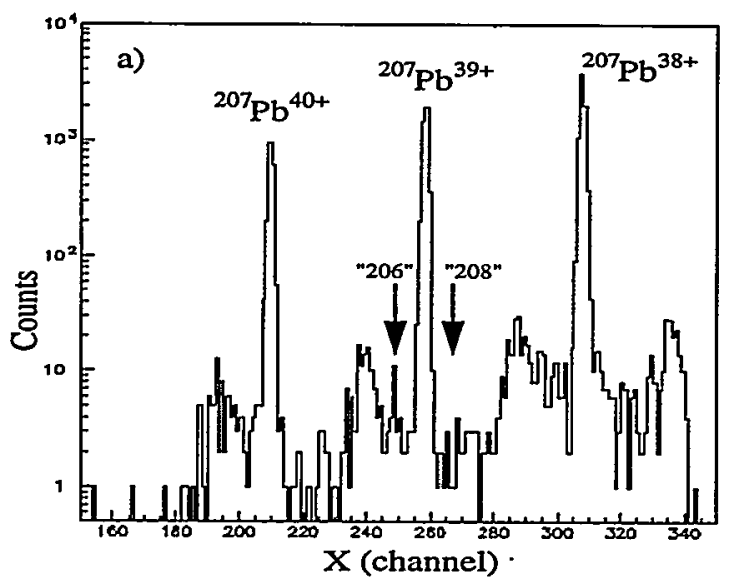

Tuned for $\quad \mathrm{M} / \mathrm{g}$

Magnet $1 \quad 207 / 21$

Magnet $2 \quad 207 / 21$

Magnet $3 \quad 207 / 21$

LINAC 207/21

FMA 207/39

Attenuation $=10^{7}$

Time $=94 \mathrm{sec}$

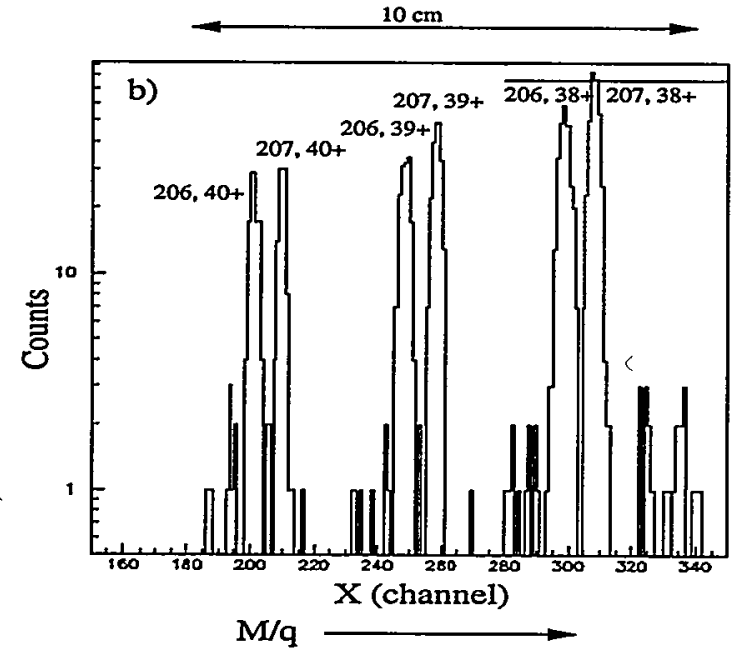

$\begin{array}{ll}\text { Magnet 1 } & 206 / 21 \\ \text { Magnet 2 } & 206 / 21 \\ \text { Magnet 3 } & 207 / 21 \\ \text { LINAC } & 207 / 21 \\ \text { FMA } & 207 / 39\end{array}$

Attenuation $=1$

Time $=1100 \mathrm{sec}$

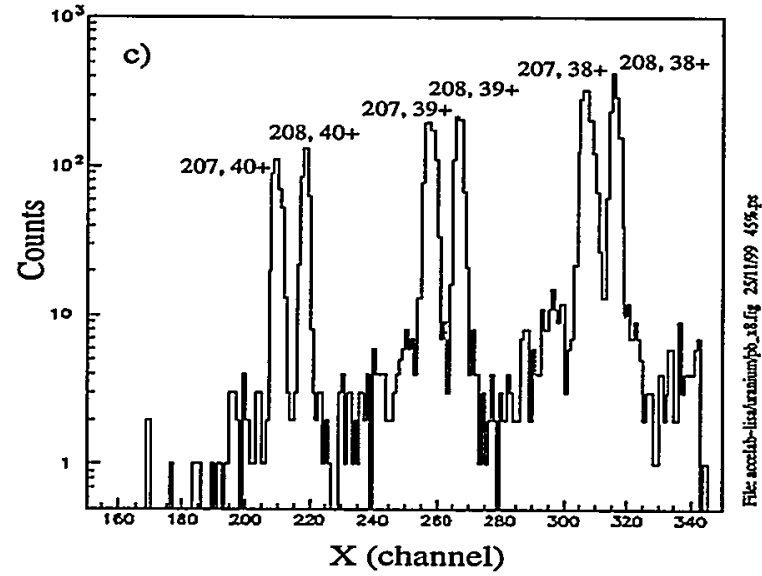

Magnet $1 \quad$ 208/21

Magnet $2 \quad 208 / 21$

Magnet $3 \quad 207 / 21$

LINAC 207/21

FMA $\quad 207 / 39$

Attenuation $=1$

Time $=1141 \mathrm{sec}$ 
FIG. 2. FMA focal plane position (m/q) spectra for $\mathrm{Pb}$ isotopes from a $\mathrm{Pb}$ sample. The righthand legend shows the $\mathrm{m} / \mathrm{q}$ tuning of the injector and the ATLAS linac for three successive measurements : a) attenuated beam of ${ }^{207} \mathrm{~Pb}^{21+}$ analyzed in the FMA after stripping; the spectrum measures the suppression power of the FMA alone for masses 206 and 208 (arrows) relative to 207 ; b) and c) ${ }^{206} \mathrm{~Pb}^{21+}$ and ${ }^{208} \mathrm{~Pb}^{21+}$ respectively injected into the linac which remained tuned as in a) to $m / q=207 / 21$. The intensities of the groups at masses 206 and 208 leaking through the linac measure the suppression power of the linac and its beam transport for adjacent masses. Quantitative analysis of the spectra results in an overall suppression power of about $1 \times 10^{-14}$.

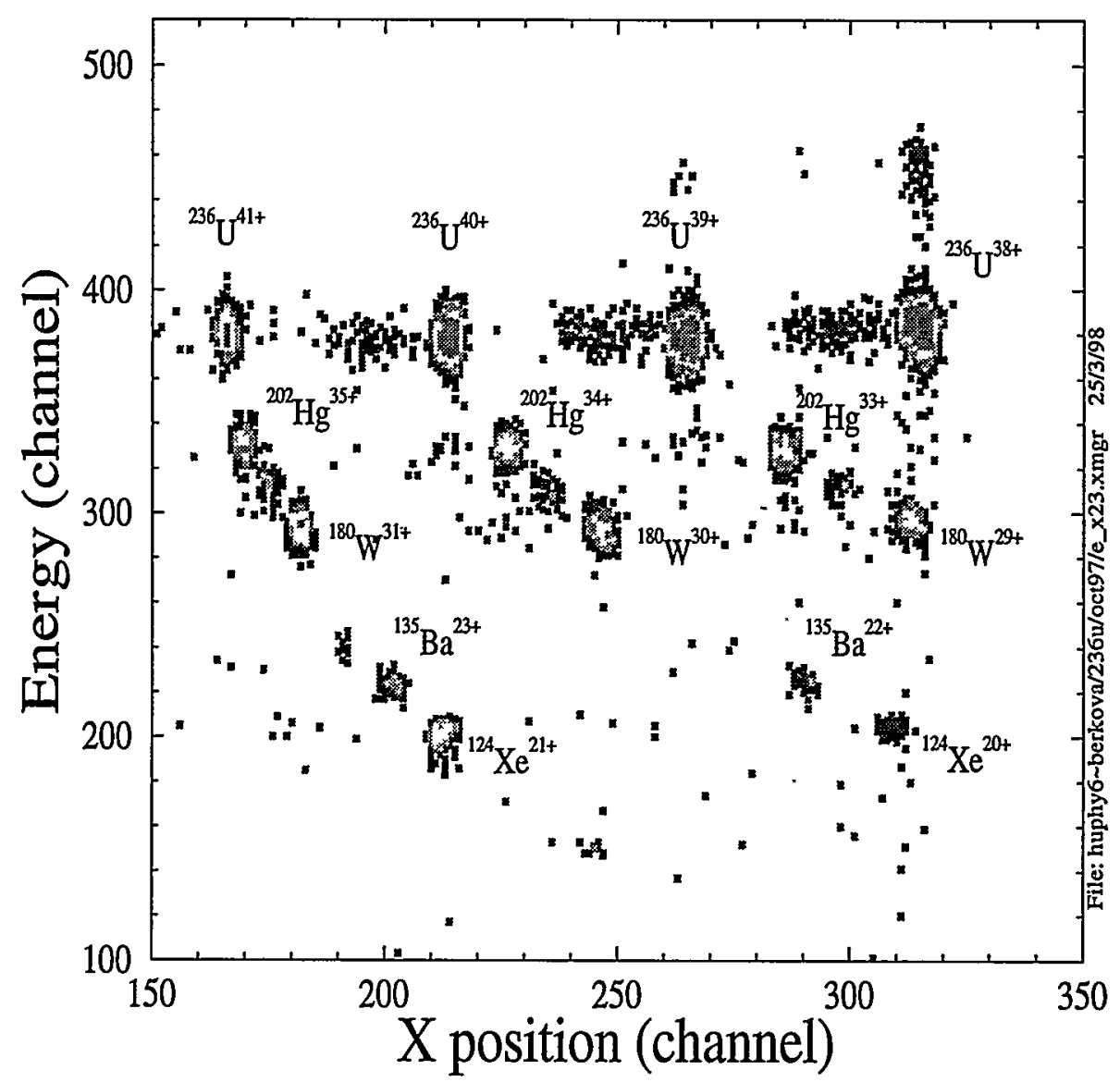

FIG. 3. Energy versus FMA position for NBS standard 950b (see text). Because of the high count rate of ${ }^{236} \mathrm{U}$ ions, the beam was attenuated by .a factor of 100 . The origin of the background isotopes (identified by their measured $\mathrm{m} / \mathrm{q}$ in the focal plane and their energy) are source sample and structure materials and source memory of past operation. Small groups of residual ${ }^{124} \mathrm{Xe}$, used as pilot beam to tune the accelerator are observed. 


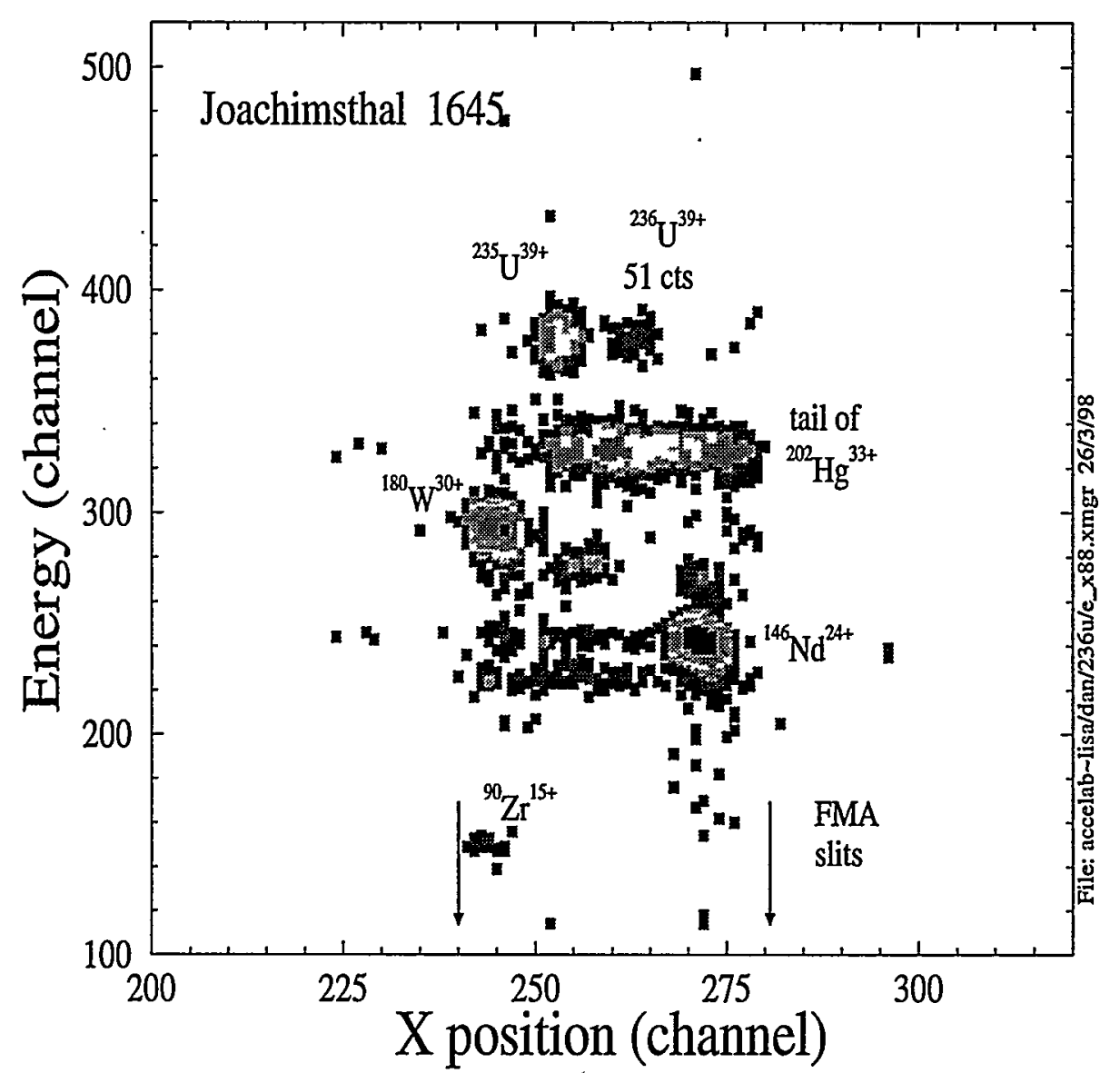

FIG. 4. Energy versus FMA position for a natural ore from Joachimsthal (see text). FMA slits were closed around ${ }^{236} \mathrm{U}^{39+}$. Measurement time was $643 \mathrm{sec}$. 